doi: 10.15407/ukrbotj75.01.033

\title{
New for Ukraine species of lichens and lichenicolous fungi from marl limestones in the Northern Black Sea Region
}

\author{
Olexander Ye. KHODOSOVTSEV ${ }^{1}$, Valeriy V. DARMOSTUK ${ }^{1,2}$ \\ ${ }^{1}$ Kherson State University \\ 27, Universytetska Str., Kherson 73000, Ukraine \\ ${ }^{2}$ Nyzhniodniprovskyi National Nature Park \\ 18, Petrenka Str., Kherson 73000, Ukraine \\ valeriy_d@i.ua
}

Khodosovtsev O.Ye., Darmostuk V.V. New for Ukraine species of lichens and lichenicolous fungi from marl limestones in the Northern Black Sea Region. Ukr. Bot. J., 2018, 75(1): 33-37.

\begin{abstract}
During the recent field season, we focused on lichens and lichenicolous fungi of petrophytic steppe habitats. They are widespread within the Black Sea Lowland in Ukraine. The marl limestones and pure limestone pebbles are outcropped in the central parts of the steppe slopes. The stone surfaces are colonized by pioneer lichen communities where endolithic life forms are mostly imperceptible. The petrophytic steppe habitats are protected in Europe. Six new for Ukraine species of lichens and two species of lichenicolous fungi from these habitats are reported in the article. A lichenicolous fungus, Acaroconium punctiforme, is characterized by subglobose black pycnidia, ampuliform conidiogenous cells, enteroblastic broadly ellipsoid aseptate pale brown conidia and Sarcogyne regularis as a host. Aspicilia subfarinosa has chalky-white thallus with farinose, smooth surface with occasional small cracks. The lichenicolous fungus Lichenochora wasseri s. 1. was found on Xanthocarpia lactea. It is a new host for this lichenicolous fungus. Psorotichia montinii has minutely areolate thin crustose to almost powdery blackish thallus, minute invisible apothecia with punctiform discs. Verrucaria bernaicensis is characterized by pale gray, epruinose, areolate or subsquamulose thallus, immersed perithecia, lacking involucrellum, and small ellipsoid ascospores. Verrucaria papillosa differs from $V$. viridula by its completely endolytic thallus and undeveloped involucrellum. Verrucaria schindleri is similar to $V$. muralis, but has dark exciple in the lower part. The localities in Ukraine, ecology and distribution data for the new records are provided.
\end{abstract}

Keywords: Acaroconium, Aspicilia, Lichenochora, Psorotichia, Verrucaria, Ukraine

\section{Introduction}

During the recent field season, we focused on the lichens and lichenicolous fungi of the petrophytic steppe habitats. These are within the Black Sea Lowland in Ukraine. Usually, the marl limestones or pure limestones pebbles are outcropped in the central parts of the steppe slopes. Over time, colonies of the pioneer lichen communities of endolithic life forms are mostly imperceptible. It is one of the first stages in biological weathering and pedogenesis. The complex of petrophytic steppe habitats is protected in Europe (Didukh et al., 2016). Six new for Ukraine species of lichens and two species of lichenicolous fungi from these habitats are presented in the article.

\section{Materials and methods}

Specimens were examined using standard light microscopy techniques with LOMO microscopes (C) O.Ye. KHODOSOVTSEV, V.V. DARMOSTUK, 2018
(MBS-1, Micromed-2) in water, $10 \% \mathrm{KOH} \mathrm{(K),}$ Lugol's iodine, directly (I) or after $\mathrm{KOH}$ pretreatment $(\mathrm{K} / \mathrm{I})$. We measured specimens in water to $0.2 \mu \mathrm{m}$ accuracy for ascospores, conidia, asci, ascomatal cells and conidiogenous cells, and to $5 \mu \mathrm{m}$ accuracy for ascomata. Measurements are given as (min-)mean$\mathrm{SD}-$ mean $+\mathrm{SD}(-\max )$. Photographs were taken with a Levenhuk C510 NG camera. All examined specimens are deposited in the lichenological herbarium of Kherson State University (KHER).The lichenicolous fungi are marked by asterisk "*". The names of lichens and lichenicolous fungi are given according to Index Fungorum, 2017 (http://www.indexfungorum.org/).

\section{Results and discussion}

*Acaroconium punctiforme Kocourk. \& D. Hawksw. (Figure, $a-c$ )

Specimen examined. Ukraine. Zaporizhzhya Region, Melitopol District, Troyitska balka, 4704'17.6" N 
$35^{\circ} 26^{\prime} 08.2^{\prime \prime} \mathrm{E}$, alt. $20 \mathrm{~m}$, on apothecia and thallus of Sarcogyne regularis, on marl limestone pebbles, 23 October 2008, A. Khodosovtsev, T. Zavyalova (KHER 10845).

Our specimen is characterized by subglobose immersed black pycnidia 55-70 $\mu \mathrm{m}$ in diam., ampuliform conidiogenous cells and enteroblastic broadly ellipsoid aseptate pale brown conidia with 1-2 oil droplet, $(5.6-) 5.8-6.6(-7.4) \times(3.0-) 3.8-4.8$ $(-5.2) \mu \mathrm{m}(\mathrm{n}=20)$. This lichenicolous fungus was reported from the Czech Republic, Germany, Slovakia and USA (Kocourková, Hawksworth, 2008).

Aspicilia subfarinosa (J. Steiner) Şenkard. \& Sohrabi Specimens examined. Ukraine. AR Crimea, Sudak District, near Sudak, Dachnoe village, alt. $700 \mathrm{~m}$, on limestone infected by Lichenostigma $\mathrm{cf}$. elongatum, 7 May 2001, A. Khodosovtsev (KHER 289 as Aspicilia farinosa); Yalta, Nature Reserve "Cape Martyan", on limestone rocks, 15 September 1999, A. Khodosovtsev (KHER 404, 405 as Aspicilia farinosa); Mykolaiv Region, Yelanetsky District, Yelanetsky Nature Reserve, balka Prusakova, on limestone, 1 December 2007, T. Boiko (KHER 4134 as Aspicilia farinosa); Novoodesky District, Mykhaylivka village, Yelanetsky Nature

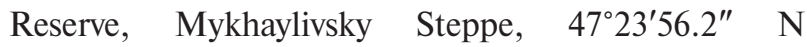
$31^{\circ} 37^{\prime} 23.5^{\prime \prime} \mathrm{E}$, alt. $16 \mathrm{~m}$, on marl limestone pebbles, 26 May 2017, A. Khodosovtsev, V. Darmostuk (KHER 10801).

This species has chalky-white thallus with farinose, smooth surface with occasional very fine cracks. In Ukraine, it was collected under the name Aspicilia farinosa (Khodosovtsev, Redchenko, 2002). The epitype of the last species refers to genus Lobothallia (Nordin et al., 2010). Aspicilia subfarinosa is known from France, Israel, Iran, Iraq, Syria, Turkey (Şenkardeşler, Sohrabi, 2011).

*Lichenochora wasseri S.Y. Kondr. s. 1.

Specimen examined. Ukraine. Kherson Region, Novovorontsovsky District, Stara Osokorivka village, $47^{\circ} 27^{\prime} 24.4^{\prime \prime} \mathrm{N} 33^{\circ} 50^{\prime} 59.3^{\prime \prime} \mathrm{E}$, alt. $50 \mathrm{~m}$, on Xanthocarpia lactea (thallus), on marl limestone pebbles, 3 June 2017, A. Khodosovtsev, V. Darmostuk (KHER 10801).

The species forms black oval to pyriform perithecia, periphyses up to $25 \mu \mathrm{m}$ long and up to $4 \mu \mathrm{m}$ wide, unitunicate asci, $60-75 \times 10-13 \mu \mathrm{m}$ and ellipsoid 1 -septate hyaline smooth walled strongly constricted at septum ascospores, (14.2-)15.0-17.2(-18.8) $\times$ (7.6-)8.2-9.2(-10.4) $\mu \mathrm{m}(\mathrm{n}=25)$. It fits well in the protologue of $L$. wasseri S.Y. Kondr. (Navrotskaya et al., 1996), but has slightly smaller ascomata $(250-360 \times 250-300 \mu \mathrm{m}$ vs. $230-280 \times 200-250 \mu \mathrm{m}$ in our specimen). Some specimens reported as "Lichenochora aff. wasseri S.Y. Kondr." on thallus of Caloplaca cf. velana from Spain (Navarro-Rosinés et al., 1998) differ by larger ascospores (10-)14-15.8-17 $(-20) \times(6.5-) 7-7.9-8.5(-9) \mu \mathrm{m}$. Xanthocarpia lactea is a new host. Previously, L. wasseri has been reported from Sweden, Israel (Navrotskaya et al., 1996) and Russia (Urbanavichus, Urbanavichene, 2014).

Psorotichia montinii (A. Massal.) Forssell

Specimen examined. Ukraine. Mykolaiv Region, Novoodesky District, Mykhaylivka village, Yelanetsky

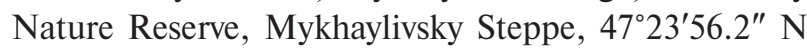
$31^{\circ} 37^{\prime} 23.5^{\prime \prime} \mathrm{E}$, alt. $16 \mathrm{~m}$, on marl limestone pebbles, 26 May 2017, A. Khodosovtsev, V. Darmostuk (KHER 10846).

Minutely areolate thin crustose to almost powdery blackish thallus, minute invisible apothecia $80-120 \mu \mathrm{m}$ in diam. with punctiform discs are diagnostic for this species. It was reported from Europe, Northern Africa and North America (Egea, 1996; Schultz, 2007; Schultz, Aptroot, 2008; Knežević, Mayrhofer, 2009; Wirth et al., 2010; Urbanavichus, Urbanavichene, 2011).

Verrucaria bernaicensis Malbr. (Figure, $d-f$ )

Specimen examined. Ukraine. Zaporizhzhya Region,

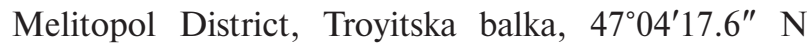
$35^{\circ} 26^{\prime} 08.2^{\prime \prime} \mathrm{E}$, alt. $20 \mathrm{~m}$, on limestone pebbles, 23 October 2008, A. Khodosovtsev, T. Zavyalova (KHER 7359).

The species is characterized by pale gray, epruinose, areolate or subsquamulose thallus, immersed perithecia 0.2-0.3 mm diam., lacking involucrellum, and small, ellipsoid ascospores (8.2-)9.4-10.0-10.8(-11.6) $\times$ $(6.5-) 7-7.9-8.5(-9) \mu \mathrm{m}$. Previously, it was known in a few European countries (Malbranche, 1869; Liskaet al., 2008; Roux, 2012), Asia (Urbanavichus, Urbanavichene, 2013) and North America (Breuss, 2007).

Verrucaria papillosa Ach. (Figure, $g-i$ )

Specimen examined. Ukraine. Mykolaiv Region, Novoodesky District, Mykhaylovka village, Yelanets

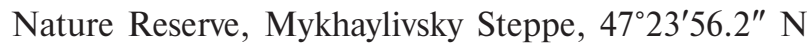
$31^{\circ} 37^{\prime} 23.5^{\prime \prime} \mathrm{E}$, alt. $16 \mathrm{~m}$, on marly limestone pebbles, 26 May 2017, A. Khodosovtsev, V. Darmostuk (KHER 10804).

It is a widely distributed species in Europe, Asia, North America and Tasmania (Breuss, 2007). Sometimes it was synonymized with Verrucaria viridula (Orange, 2004), but the last one differs by usually 

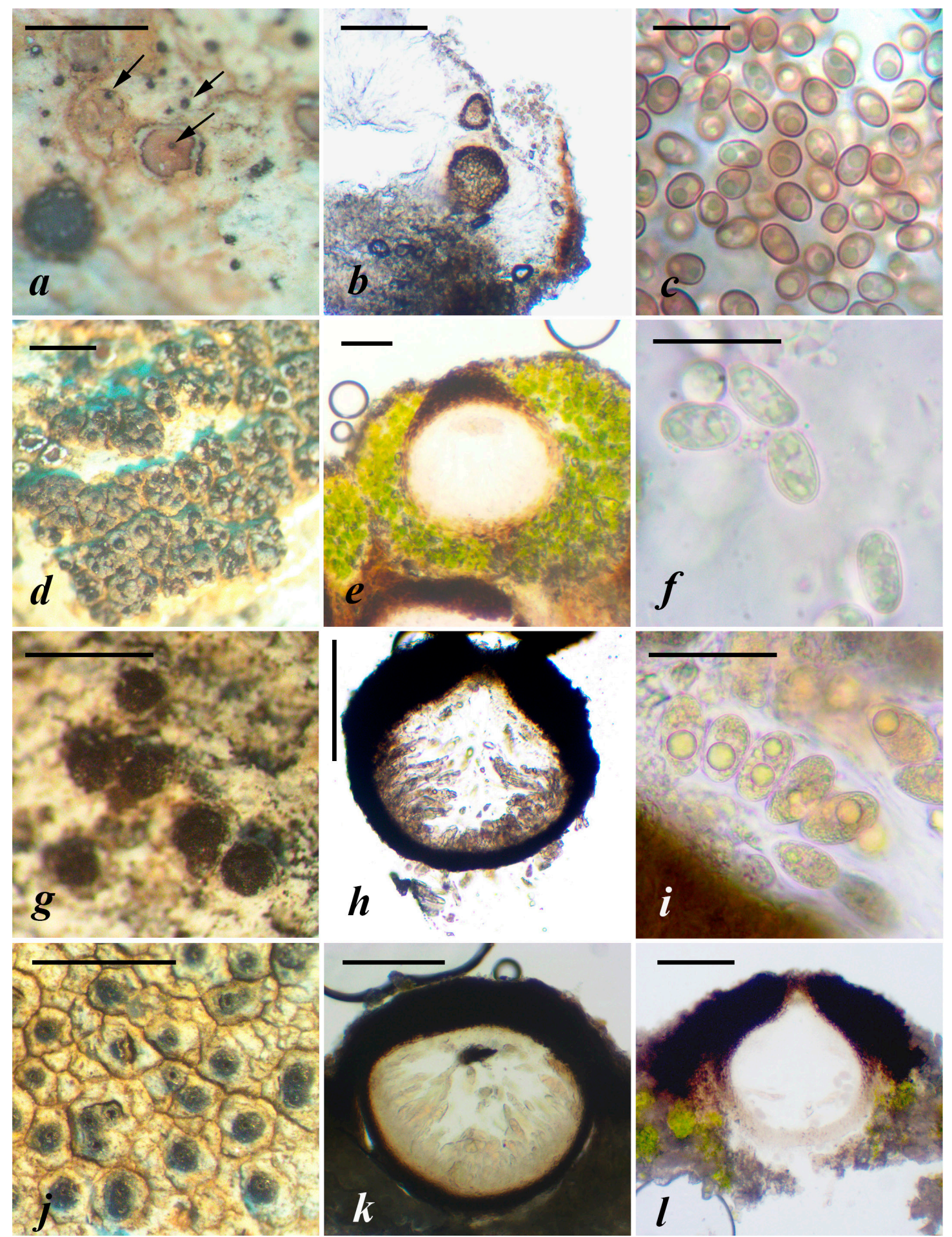

Acaroconium punctiforme: $a$ - infected apothecia of Sarcogyne regularis (scale $1 \mathrm{~mm}$ ), $b$ - section through pycnidia (scale $100 \mu \mathrm{m}$ ), $c$-conidia (scale $10 \mu \mathrm{m}$ ). Verrucaria bernaicensis: $d$-general habit (scale $1 \mathrm{~mm}$ ), $e$-section through perithecia (scale $100 \mu \mathrm{m}$ ), $f$-ascospores (scale $10 \mu \mathrm{m}$ ). Verrucaria papillosa: $g$ - general habit (scale $1 \mathrm{~mm}$ ), $h$-section through perithecia (scale $200 \mu \mathrm{m}$ ), $i$ - ascospores (scale $25 \mu \mathrm{m}$ ). Verrucaria schindleri (KHER 10847): $j$ - general habit (scale $1 \mathrm{~mm}$ ), $k$ - section through perithecia (scale $150 \mu \mathrm{m})$. Verrucaria muralis $($ KHER 7563): $l$ - section through perithecia (scale $150 \mu \mathrm{m})$ 
greenish brown to dark brown epilithic thallus, and a small apical involucrellum.

Verrucaria schindleri Servít (Figure, $j-k$ )

Specimens examined. Ukraine. Mykolaiv Region, Bereznehuvate District, Prishyb village, $47^{\circ} 12^{\prime} 48.6^{\prime \prime} \mathrm{N}$ $32^{\circ} 50^{\prime} 14.9^{\prime \prime} \mathrm{E}$, alt. $44 \mathrm{~m}$, on marl limestone pebbles, 31 May 2017, A. Khodosovtsev, V. Darmostuk (KHER 10847); Novoodesky District, village Mykhaylivka, Yelanetsky Nature Reserve, Mykhaylivsky Steppe, $47^{\circ} 23^{\prime} 56.2^{\prime \prime} \mathrm{N} 31^{\circ} 37^{\prime} 23.5^{\prime \prime} \mathrm{E}$, alt. $16 \mathrm{~m}$, on marl limestone pebbles, 26 May 2017, A. Khodosovtsev, V. Darmostuk (KHER 10800); Kherson Region, Beryslav District, Dudchany village, $47^{\circ} 06^{\prime} 27.2^{\prime \prime} \mathrm{N}$ $33^{\circ} 41^{\prime} 01.8^{\prime \prime} \mathrm{E}$, alt. $25 \mathrm{~m}$, on marl limestone pebbles, 4 June 2017, A. Khodosovtsev, V. Darmostuk (KHER 10812); Novovorontsovsky District, Gavrylovka

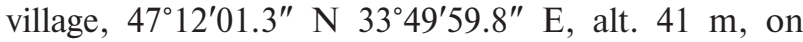
marl limestone pebbles, 30 July 2017, A. Khodosovtsev, V. Darmostuk (KHER 10811); Zaporizhzhya Region, Melitopol District, Troyitska balka, 4704'17.6" N $35^{\circ} 26^{\prime} 08.2^{\prime \prime} \mathrm{E}$, alt. $20 \mathrm{~m}$, on marl limestone pebbles, 23 October 2008, A. Khodosovtsev, T. Zavyalova (KHER 7362).

Additional specimen examined. Verrucaria muralis (Figure, l): Kherson Region, Beryslav District, near Mylove village, on limestone, 19 July 2008, A. Khodosovtsev,L. Gavrylenko (KHER 7563).

Verrucaria schindleri is very similar to $V$. muralis. The first species differs by blackish brown exciple even in thin sections. It is widely distributed in Europe (Servít, 1948; Søchting, Alstrup, 2008; Heiðmarsson et al., 2009; Wirth et al., 2010; Strasser et al., 2015) and poorly known in Northern America (Breuss, 2007).

\section{Acknowledgments}

Yakiv Didukh, Ganna Naumovich, Ivan Moysiyenko and Igor Pylypenko were of indispensable assistance during fieldwork excursions. This study was financially supported by the Ministry of Science and Education of Ukraine (Project No. 0116U004735).

\section{REFERENCES}

Breuss O. Verrucaria. In: Lichen Flora of the Greater Sonoran Desert Region. Eds T.H. Nash III, C. Gries,F. Bungartz. Tempe: Arizona State Univ., 2007, vol. 3, pp. 335-377.

Biotopes of the Crimean Mountains. Ed. Ya.P. Didukh. Kyiv: Interservis, 2016, 292 pp. [Біотопи Гірського Криму. Ред. Я.П. Дідух. Киів: ТОВ "НВП Інтерсервіс", 2016, 292 c.].

Egea J.M. Catalogue of lichenized and lichenicolous fungi of Morocco. Bocconea, 1996, 6: 19-114.
Heiðmarsson S., Alstrup V., Högnabba F., Motiejūnaitė J., Nordin A., Pykälä J., Suija A., Timdal E., Westberg M. Floristic news from the NLF Iceland excursion 2009. Graphis Scripta, 2009, 24: 19-25.

Khodosovtsev A.Ye., Redchenko O.O. Ukr. Bot. J., 2002, 59(1): 64-71. [Ходосовцев О.С., Редченко О.О. Анотований список лишайників заповідника "Мис Март'ян" (Україна). Укр. бот. журн., 2002, 59(1): 64$71]$.

Knežević B., Mayrhofer H. Catalogue of the lichenized and lichenicolous fungi of Montenegro. Phyton, 2009, 48(2): 283-328.

Kocourková J., Hawksworth D.L. Acaroconium punctiforme gen. sp. nov., a new lichenicolous coelomycete on Acarospora species and Sarcogyne regularis. Lichenologist, 2008, 40(2): 105-109.

Liska J., Palice Z., Slavikova S. Checklist and Red List of lichens of the Czech Republic. Preslia, 2008, 80(2): 151-182.

Malbranche A. Lichens de la Normandie ou Catalogue descriptif des Lichens de cette région, classés d'après la méthode du docteur Nylander. Bull. Soc. Amis Sci. Natur. Musée de Rouen, 1869: 335-369.

Navarro-Rosinés P., Boqueras M., Roux C. Nuevos datos para el género Lichenochora (Phyllachorales, Ascomicetes liquenícolas). Bull. Soc. Linn. Provence, 1998, 49: $107-124$.

Navrotskaya I.L., Kondratyuk S.Ya., Wasser S.P., Nevo E., Zelenko S.D. Lichens and lichenicolous fungi new for Israel and other countries. Israel J. Plant Sci., 1996, 44(2-3): 181-193.

Nordin A., Savic S., Tibell L. Phylogeny and taxonomy of Aspicilia and Megasporaceae. Mycologia, 2010, 102(6): 1339-1349.

Orange A. The Verrucaria fuscella group in Great Britain and Ireland. Lichenologist, 2004, 36(2): 173-182.

Roux C. Liste des lichens et champignons lichénicoles de France. Bull. Soc. Linn. Provence, 2012, 16: 1-220.

Şenkardeşler A., Sohrabi M. Aspicilia subfarinosa, the correct name for A. substerilis. Mycotaxon, 2011, 115(1): 99-106.

Schultz M. Psorotichia. In: Lichen Flora of the Greater Sonoran Desert Region. Eds T.H. Nash III, C. Gries, F. Bungartz. Tempe: Arizona State Univ., 2007, vol. 3, pp. 279-284.

Schultz M., Aptroot A. Notes on poorly known, small cyanobacterial lichens from predominantly wet tropical to subtropical regions. Sauteria, 2008, 15: 433-458.

Servít M. Species novae generis lichenum Verrucaria. Vestn. Kral. Ceske Spolecn. Nauk, 1948, 10: 1-20.

Søchting U., Alstrup V. Danish lichen checklist. København: Museum Tusculanum, 2008, $46 \mathrm{pp}$.

Strasser E.A., Hafellner J., Stešević D., Geci F., Mayrhofer $\mathrm{H}$. Lichenized and lichenicolous fungi from the Albanian Alps (Kosovo, Montenegro). Herzogia, 2015, 28(2): 520-544.

Urbanavichus G., Urbanavichene I. New records of lichens and lichenicolous fungi from the Ural Mountains, Russia. Folia Cryptogam. Estonica, 2011, 48: 119-124.

Ukr. Bot. J., 2018, 75(1) 
Urbanavichus G., Urbanavichene I. New records of pyrenocarpous lichens from the NW Caucasus (Russia). Herzogia, 2013, 26: 123-129.

Urbanavichus G., Urbanavichene I. An inventory of the lichen flora of Lagonaki Highland (NW Caucasus, Russia). Herzogia, 2014, 27: 285-319.

Wirth V., Hauck M., von Brackel W., Cezanne R., de Bruyn U., Dürhammer O., Eichler M., Gnüchtel A., Litterski B., Otte V., Schiefelbein U., Scholz P., Schultz M., Stordeur R., Feuerer T., Heinrich D., John V. Checklist of lichens and lichenicolous fungi in Germany. Göttingen: Georg August Univ. Göttingen, 2010, 236 pp.

Recommended for publication by

Submitted 27.11.2017

S.Ya. Kondratyuk

Ходосовцев О.Е. ${ }^{1}$, Дармостук В.В. ${ }^{1,2}$ Нові для України види лишайників та ліхенофільних грибів 3 мергелістих вапняків Північного Причорномор'я. Укр. бот. журн., 2018, 75(1): 33-37.

${ }^{1}$ Херсонський державний університет

вул. Університетська, 27, Херсон 73000, Україна

${ }^{2}$ Національний природний парк

"Нижньодніпровський",

вул. Петренка, 18, Херсон 73000, Україна

Протягом останнього польового сезону досліджували лишайники і ліхенофільні гриби в петрофітних степових біотопах. Вони поширені в межах Причорноморської низовини, де в середній частині степових схилів вимиваються вапнякові та мергелисті камінці. Згодом їх колонізують піонерні лишайникові угруповання, де переважають ендолітні життєві форми. Комплекс петрофітих степових біотопів охороняється в Європі. У статті представлена інформація щодо знахідок шести нових для України видів лишайників і двох видів ліхенофільних грибів, знайдених в цих біотопах. Ліхенофільний гриб Acaroconium punctiforme характеризується субглобулярними чорними пікнідами, ампулоподібними конідіогенними клітинами, ентеробластичними широкоеліпсоїдними несептованими блідо-коричневими конідіями і зростає на Sarcogyne regularis. Лишайник Aspicilia subfarinosa має одноманітно-накипну білу слань 3 гладкою поверхнею i нерегулярними дуже дрібними тріщинками. Ліхенофільний гриб Lichenochora wasseri s. 1. був виявлений на Xanthocarpia lactea, який $€$ його новим господарем. Psorotichia montinii утворює дуже тонку, чорну слань, дрібні непомітні апотеції 3 точкоподібним диском. Verrucaria bernaicensis характеризується блідосірою, ареольованою, сланню, зануреними перитеціями і невеликими еліпсоїдними аскоспорами. Verrucaria papillosa відрізняється від $V$. viridula повністю ендолітною сланню і нерозвиненим вкривальцем, V. schindleri схожий на $V$. muralis, але має темний ексціпул у нижній частині. У статті також наведено всі місцезнаходження знайдених видів, їхні екологічні особливості та поширення в світі.

Ключові слова: Acaroconium, Aspicilia, Lichenochora, Psorotichia, Verrucaria, Україна

Ходосовцев А.Е. ${ }^{1}$, Дармостук В.В. ${ }^{1,2}$ Новые для Украины виды лишайников и лихенофильных грибов с мергелистых известняков Северного Причерноморья. Укр. бот. журн., 2018, 75(1): 33-37.

${ }^{1}$ Херсонский государственный университет, ул. Университетская, 27, Херсон 73000, Украина

${ }^{2}$ Национальный природный парк "Нижнеднепровский", ул. Петренко, 18, Херсон 73000, Украина

В течение последнего полевого сезона изучали лишайники и лихенофильные грибы в петрофитных степных биотопах. Они распространены в пределах Причерноморской низменности, где в средней части степных склонов вымываются известняковые и мергелистые камешки. Со временем их колонизируют пионерные лишайниковые сообщества, где преобладают эндолитные жизненные формы. Комплекс петрофитных степных биотопов охраняется в Европе. В статье представлена информация о находках шести новых для Украины видов лишайников и двух видов лихенофильных грибов, найденных в этих биотопах. Лихенофильный гриб Acaroconium punctiforme характеризуется субглобулярными чёрными пикнидами, ампулообразными конидиогенными клетками, энтеробластическими широкоэллипсоидными несептированными бледно-коричневыми конидиями и произрастанием на Sarcogyne regularis. Лишайник Aspicilia subfarinosa имеет однообразно накипное белое слоевище с гладкой поверхностью и случайными очень мелкими трещинками. Лихенофильный гриб Lichenochora wasseri s. 1. был обнаружен на Xanthocarpia lactea, который является его новым хозяином. Psorotichia montinii образует очень тонкое, черное слоевище, мелкие незаметные апотеции с точковидным диском. Verrucaria bernaicensis характеризуется бледно-серым, ареолированным, слоевищем, погруженными перитециями и небольшими эллипсоидными аскоспорами. Verrucaria papillosa отличается от $V$. viridula полностью эндолитным слоевищем и неразвитым покрывальцем, $V$. schindleri похож на V. muralis, но имеет темный эксципул в нижней части. В статье также приведены все местонахождения найденных видов, экологические особенности и распространение в мире.

Ключевые слова: Acaroconium, Aspicilia, Lichenochora, Psorotichia, Verrucaria, Украина 